\title{
scripted
}

Volume 9, Issue 2, August 2012

\section{SCRIPT, SCRIPTED AND ONWARDS}

Nayha Sethi and Yolande Stolte*

DOI: $10.2966 /$ scrip.090212.127

\section{(c) (i) (9)}

(C) Nayha Sethi and Yolande Stolte 2012. This work is licensed under a Creative Commons Licence. Please click on the link to read the terms and conditions.

\footnotetext{
* University of Edinburgh
} 


\section{SCRIPT}

The Arts and Humanities Research Council Centre for Studies in Intellectual Property and Technology Law at the University of Edinburgh ('SCRIPT') celebrated its 10th anniversary. In celebration, a conference was held at Surgeon's Hall in Edinburgh on 6th, 7th and 8th June on the overarching theme of Law and Transformation.

A workshop for PhD students and Early Career Researchers was held on the first day, with a key note speech from Nadia Kanellopoulou offering valuable advice on working within academia. Participants had the opportunity to present their work and gain feedback from notable experts in their respective fields (medical, intellectual property and information technology law). The second day of the conference was centred on regulation and trust. Baroness Onora O'Neill delivered her keynote speech focussing on the importance of trust and specifically, trustworthiness within Communications. The Baroness highlighted 5 key requirements for ensuring openness in the Media, including openness about: payments from others, payment to others, interests, errors and sources. The final day, focusing on openness and secrecy, began with an address from Lord Inglewood, Chair of the House of Lords Communications Committee. The talk discussed 'Investigative Journalism and the Public Interest'. Lord Inglewood stressed the importance of balancing principles in the context of data protection legislation, the Official Secrets Act (1989) and the public interest defence. Both keynote speeches were given in the wake of the recent media phone-hacking scandals and resonated well with SCRIPTs continued efforts to respond to how the law can best be deployed to address such challenges. During parallel sessions and in accordance with the conference themes, expert panels addressed pertinent issues arising in their respective fields. Industry leaders were invited to round-table discussions where discussions focussed on how academic research could have real world impact in their respective fields. Celebrated Scottish science-fiction writer Ken MacLeod entertained guests at the conference dinner, offering a reflective note on how life can imitate art and the fact that reality sometimes catches up with science fiction novels, while new science can provide inspiration for fiction. After dinner, delegates were offered some insight in to Scottish culture with a ceilidh and some enthusiastic dancing from participants. The conference concluded with an address from the SCRIPT Centre Director, Professor Burkhard Schafer, who recounted some of the most memorable and successful moments for the Centre and paid homage to all of its members, past and present.

While the funding of the Arts and Humanities Research Council, which has supported the SCRIPT Centre for the past 10 years, has now come to an end the Centre and its resultant streams (medical, IP, IT and Media Law) will continue to innovate and collaborate and respond to new regulatory challenges, as they have done for the last 10 years.

\section{SCRIPTed}

SCRIPTed has been associated with the SCRIPT Centre since the inception of the journal more than eight years ago and has benefited from a grant which has supported the journal over the years. Alongside this grant SCRIPTed has benefitted from a large number of volunteers from the postgraduate community at the Edinburgh Law School, 
many of who have stayed with us for several years and provided an invaluable contribution to keeping the journal running.

The editorial board will see some changes next year as Yolande Stolte will be stepping down as Editor-in-Chief and Nayha Sethi, our current Managing Editor, will take over the position, with recruitment for the new Managing Editor still ongoing. We're also saying goodbye to Abbe Brown, our Supervising Editor for the IT section, and welcoming Daithí Mac Síthigh to the role.

While our funding has now come to an end we will continue to run SCRIPTed with the help of our volunteer staff while exploring new funding oppertunities. We would like to thank the AHRC and SCRIPT for their generous support over the years. 